\title{
OVER-REPORTING INTIMATE PARTNER VIOLENCE IN AUSTRALIAN SURVEY RESEARCH
}

\author{
JefFrey M. Ackerman*
}

This research, inspired by the cognitive interviewing literature, investigates misreporting of intimate partner violence when survey participants interpret items in unintended ways. In over 23 per cent of victimizations reported by university-aged males and in over 12 per cent of victimizations reported by females, follow-up questions revealed that purported violence was either accidental or done in a manner where neither partner took the event seriously. The problem was worse for perpetration reports where over 47 per cent of male reports and over 17 per cent of female reports were endorsed in a manner unintended by instrument design. The magnitude of the problem, together with its gendered nature, suggests that misreporting of this type is a substantial problem having the potential to negatively affect the testing of partner-violence theories.

Keywords: intimate partner violence, domestic violence, conflict tactics scale

\section{Introduction}

Since at least 1975 when University of New Hampshire (United States) sociologist Murray Straus and colleagues (1979) conducted the first large-scale survey about family violence in the United States, survey data have played an important role in research on familial violence. Perhaps most importantly, evidence from surveys has informed government officials, the media, and the general public about the extent of this violence in ways that have positively affected public awareness, public policy and amelioration initiatives (DeKeseredy and Schwartz 1998). As a result, family violence in general, and intimate partner violence (IPV) more specifically, have become recognized as major social problems in Western countries (Kline et al. 1997).

Considerable disagreement exists, however, about the accuracy of survey-based IPV research findings, which often conflict with several theoretical assumptions about IPV aetiology and with conclusions drawn from alternative data sources such as lawenforcement or medical records (Johnson 1995). One example of this conflict is that information gathered from the most influential and common of the IPV scales used in survey research, Straus and colleagues' conflict tactics scale (CTS) consistently leads to conclusions that women behave as violently towards their intimate partners as do men. Analyses of alternative data sources, however, suggest otherwise (Taft et al., 2001). A second example is that survey research has not yet uncovered associations between male-perpetrated partner violence and the patriarchal attitudes, values and beliefs that various feminist theories suggest as its primary cause (Felson et al. 2003; Bates et al. 2014).

Several controversies about survey-based IPV research accuracy may best be framed as questions about the extent to which partner violence is misreported, i.e. how often

*Jeffrey M. Ackerman, School of Criminology and Criminal Justice, Griffith University, Southport, QLD 4222, Australia; j.ackerman@griffith.edu.au. 
respondents fail to report actual cases of IPV (under-reports) and how often they overreport events they should not (Fuchs 2008). A common assertion is that victims underreport violent behaviour due to embarrassment, fear of reprisal, shame or a reluctance to recall traumatic memories (DeKeseredy and Schwartz 1998). Victims may also fail to 2.5 report events they deem too trivial or inconsequential (DeKeseredy 1995). In a parallel fashion, perpetrators may under-report the violence they direct at partners for reasons similar to why they under-report other socially undesirable acts (Foddy 1993; Smith 1994).

Although the IPV literature has thoroughly discussed matters of potential underreporting, there are few, if any, studies that focus on the over-reporting of IPV. In the

2.10 present context, over-reporting, means the endorsement of survey items about aggressive acts under conditions where neutral third parties would not have considered the event as IPV. Later portions of this paper elaborate upon this definition.

The lack of empirically based assessments of IPV over-reporting is surprising given how problematic over-reporting becomes if it occurs differentially among the demo2.15 graphic groups scholars wish to compare (Hamby 2014b). For example, perhaps men over-report female-perpetrated aggression, while women more accurately report the aggressive behaviour of male partners. If so, this could explain the gender-symmetry findings found in survey research that contrast is so sharply with findings from alternative data sources and with many of the fundamental assertions of feminist theories (Kimmel 2002).

Regardless of whether over-reporting explains the gender-symmetry controversy, however, gender differences in over-reporting clearly have serious implications for testing any theoretical perspective where accurate accounting of the gendered patterns of violence matter. For this reason, the extent to which IPV over-reporting occurs in survey data is worthy of careful investigation.

\section{IPV Definitions and the CTS}

The CTS is the most influential and widely used measure of partner violence (Langhinrichsen-Rohling 2005). The scale uses a definition of violence that is among the most inclusive: 'an act carried out with the intention of, or perceived as having the intention of, physically hurting another person' (Gelles and Straus 1979: 554). The scale's corresponding instructional preamble is:

No matter how well a couple gets along, there are times when they disagree, get annoyed with the other person, want different things from each other, or just have spats or fights because they are in a bad mood, are tired, or for some other reason. Couples also have many different ways of trying to settle their differences. This is a list of things that might happen when you have differences. Please mark how many times you did each of these things in the past year, and how many times your partner did them in the past year. ...

The CTS preamble corresponds to all of several items that describe various forms of aggression/violence of the form:

I slapped my partner/my partner slapped me

2.45 The CTS purposely uses behavioural rather than legal language (Hamby 2014b). It was designed to increase disclosure of sensitive, emotionally charged or otherwise socially 2.47 undesirable events by de-stigmatizing them. Part of that strategy involves the avoidance 
of specific words like 'abuse' or 'battering'. We know, however, that large variation in interpretation across respondents is particularly likely when questions contain imprecise terminology (Fuchs 2008). More specifically, Straus and colleagues' definition has been criticized for being overly inclusive and their preamble for containing 'ideological and factual assumptions ... such as the notion that battery is the result of an argument' (DeKeseredy and Schwartz 1998).

\section{Misreporting and the cognitive interviewing literature}

Although some scholars have proclaimed that no convincing theoretical reason exists to assume that over-reporting of IPV occurs (Smith 1994), others have provided sound, but often empirically untested, explanations for the conditions that might lead to this problem in partner violence research. One set of explanations about over-reports in IPV surveys focuses upon the potential for victims or perpetrators to intentionally claim an assault occurred when it did not. A parent, e.g. may fictitiously report domestic assault victimization to the authorities to leverage divorce or custody proceedings and may mimic their fictitious report in a survey (Gadd et al. 2002). Similarly, portions of the feminist literature suggest that males may report victimizations at the hands of female partners that did not actually occur to justify their own perpetration against partners (Kimmel 2002) or to otherwise depict themselves as victims to reduce blame (Gadd et al. 2002).

Cognitive interviewing became more popular after a 1984 interdisciplinary seminar on survey methodology (Beatty and Willis 2007), years after the CTS was developed. According to this literature, unintentional mechanisms often cause over-reporting due to differences between the intent of survey designers and the meaning participants attribute to survey items (Belson 1981; Foddy 1993). While some scholars find it difficult to understand how respondents have different interpretations of carefully worded questions, theory within the cognitive interviewing and survey design literatures suggests that survey participants frequently interpret the conceptual meaning within survey questions in unintended ways (Tourangeau et al. 2000; Beatty and Willis 2007). These literatures describe pre-testing interviews designed to uncover and resolve potential attributional and conceptual problems of item wording. An important realization from this literature, adeptly illustrated by Beatty and Willis, is that item wording adequate for certain groups may fail among others.

Consider the question: 'Are you currently being treated by a doctor for arthritis?' ... this question is simple for participants with either serious arthritis or no arthritis at all. However, it can be complicated for participants whose circumstances may not quality as 'current treatment' (e.g., those who have seen a doctor for arthritis pain over a year ago). Does this qualify as a 'problem' with the question? If so, it might make sense to add more specific language than 'current treatment.' However, doing so would make the question longer, more burdensome, and potentially confusing to respondents who did not have difficulty with the original version (Straus 1979).

Belson (1981) provided empirical evidence of the high variance among survey participants in the interpretation of common words such as 'usually', 'generally', 'people', 'children', and 'weekday'. If these common terms are so easily interpreted in different ways, imagine how varied the interpretations of words such as 'hitting' or 'slapping' may be when measuring IPV. 
Dobash and colleagues eloquently described a major aspect of this problem for IPV measurement:

Consider a 'slap.' The word encompasses anything from a slap on the hand chastising a dinner 4.5 companion for reaching for a bite of one's dessert to a tooth-loosening assault intended to punish, humiliate, and terrorize. These are not trivial distinctions; indeed, they constitute the essence of definitional issues concerning violence (1992: 79).

This is a key point. The CTS definition and instructional preamble might motivate a survey respondent to interpret a 'slap' received from a partner in a playful or light4.10 hearted manner, which caused no alarm to the respondent, as one worthy of reporting. Certainly such a report would be outside the conceptual meaning of 'violence' as understood by most people.

Dobash and colleagues have further argued that if some respondents interpret phrases such as 'tried to hit with an object' literally, a good deal of harmless behaviour 4.15 will contaminate IPV estimates. Moreover, they suggest that although CTS items may appear behaviourally specific and refer to carefully described actions, question meanings can still be interpreted in ways much different from the scale designer's intent.

Perhaps the endorsement of CTS items is similar to the arthritis example mentioned above. Victims of serious partner violence may readily endorse an item enquiring about 4.20 whether their partner 'hit' them. Likewise, highly educated and mature adults in the most healthy of romantic relationships may not hesitate in not endorsing a similar item. For other survey participants, however, the interpretation and endorsement of this question may be less clear.

Although matters of item interpretation on IPV survey items have not received much 4.25 empirical assessment to date, literature about the fear of crime contains clear illustrations of problematic question interpretation. Farrall and colleagues (1997), e.g. compared quantitative responses about the fear of crime as measured by a five-point scale where (1) represented 'not being worried at all' and (5) meant 'worrying a lot, all the time' with information gained from cognitive interviews. A substantial number of 4.30 males who answered in the 5-'all of the time' category-subsequently clarified that from the survey designer's perspective, the most appropriate answer would have been situationally dependent upon the time of day. These scholars provided the example of an in-depth cognitive interview where a male respondent explained that he mostly worried about crime at night around groups of people but worried little at home during 4.35 the day. For this reason, the answer on his quantitative question could be considered correct at either a 1 or a 5 , or perhaps even a 3 , the average for the three time periods. These scholars found that mismatches of this type occurred for 19 per cent of their sample.

Sutton and colleagues (2005) illustrated the serious problems that arise when demo4.40 graphic groups systematically differ in question interpretation or event reporting. Using instruments containing a fear of crime scale and an inventory designed to measure socially desirable response patterns, they found that women's purportedly greater fear of crime could be explained by a decreased willingness to report fear among men. Gender differences disappeared after accounting for reporting differences.

4.45 Although anecdotes about problems with IPV measurement have occasionally been noted, until recently systematic examinations of the problems' extent are rare or non4.47 existent (Lehrner and Allen 2014). More specifically, if a respondent reports events that 
have actually occurred, but that no objective observer (or possibly no respondent themselves) would classify as actual partner violence because the respondent misunderstood an item's intent, over-reporting in the form of an unintentional over-report will occur. Margolin (1987), e.g. described a case where a survey respondent endorsed an item about being 'kicked' by a partner but explained during a follow-up interview that the kick occurred in a light-hearted manner and was not viewed as aggressive by either party.

\section{Over-reporting Versus Over-estimation}

Before proceeding, I should clarify the term 'over-report' as used in this manuscript. Herein, the term refers to a specific type of misreporting in the form of a false-positive on an individual survey item endorsed by an individual respondent. Over-reporting defined in this way does not necessarily imply over-estimation of IPV rates at the population level. Over-reports and under-reports may simultaneously occur in the same survey (Messing and Thaller 2013). For this reason, even if many individuals over-report IPV events, underestimation of population prevalence may still occur if the number of under-reporting participants exceeds those who over-report.

It is important to emphasize this point so readers do not misconstrue the intent of this research as an attempt to downplay the frequency or seriousness of partner violence. Prior discussions about over-reports of this type, in fact, are most frequently found in feminist scholarship, the primary literature emphasizing IPV's frequency and severity. Feminist theorists have long questioned certain survey-based conclusions, often due to assumptions that males are particularly prone to inaccurate IPV reports.

\section{The Present Research}

Although a primary CTS critique is its failure to measure the context, meaning and motivation of aggressive acts (DeKeseredy 1995), few quantitative studies have attempted to do this with the exception of those examining the extent to which respondents endorse items best characterized as self-defence (Saunders 1986). The present study, inspired by the theoretical and methodological insights of the cognitive interviewing literature, addresses this shortcoming by using supplementary questions to inquire about important contextual details of positively endorsed partner violence events in an IPV survey administered to a sample of Australian university students.

A primary purpose of the supplementary questions was to assess whether unintentional over-reporting occurred. Ideally, cognitive interviewing would be used to detect this problem during instrument development. Unfortunately, the CTS was developed by other scholars prior to the more widespread use of these interviewing techniques. Moreover, even when these techniques uncover potential problems, there is often no obvious way to verify their substance unless quantitative tests are performed after survey administration (Willis and Schecter 1997).

Performing such an assessment specific to the CTS is important for two primary reasons. First, the CTS is extensively used for estimating IPV prevalence and testing IPV theories. Second, the CTS has often been used as a criterion standard by which other instruments have been evaluated for sensitivity, specificity, and related psychometric properties (Reichenheim and Moraes 2004). 
The use of university student samples to make such an assessment, at least as a preliminary step before replicating this research on samples more representative of a wider population, is justified for at least two reasons. First, because the CTS was intended to be valid across all sub-populations, and second, because widely reported research

6.5 results regarding IPV among university students have been published based upon this scale (Straus 2004).

The assumed cause of the unintentional over-reports examined herein is 'meaning shifts', which occur during the interpretation of survey questions (Gaskell et al. 1994). According to the survey design literature, respondents go through several stages dur6.10 ing survey participation. During the comprehension stage of Tourangeau and colleagues' model of the question-answer process, respondents attempt to understand a question's words and phrases, general meaning and the question writer's intent (Tourangeau et al. 2000). Research in this literature shows that conceptual meaning within questions is frequently understood in unintended ways during this stage.

6.15 If a respondent positively endorses a CTS item but subsequently endorses items about the event being an accident or being performed under conditions where neither party interpreted the event seriously, an over-report has occurred. Although exact definitions of IPV vary among scholars in ways where some are more inclusive of less-serious events than others (Pagelow 1979), no scholar suggests that events such as accidents or behaviours that both partners consider playful be considered IPV.

One potential complication of this assumption is that some scholars suggest that IPV victims may occasionally downplay the seriousness of the violence to which they are exposed (Smith 1994). There are four issues to consider when evaluating this suggestion for the current study: (1) the primary purpose of the present research is to 6.25 determine under what conditions over-reporting is most likely to occur rather than to provide a method producing precise prevalence estimates; (2) much of the IPV research focuses on complete denial of IPV among survey participants, with less evidence-based concern about downplaying event seriousness once reported (Hamby 2014a); (3) several scholars have convincingly argued that it is generally best to rely upon a victims' 6.30 perceptions of what constitutes abuse rather than have researchers do this themselves. According to some authors, a fundamental principle in feminist scholarship is to listen to the subjective interpretations of a victim's experience (Gartner 1993); and (4) recent scholarship relying upon data from several Western countries strongly indicates that IPV victims do not deny or minimize their problems, but rather seek help from a variety

6.35 of sources at rates equal to or greater than the rates at which they seek help for other serious problems (Sullivan et al. 2010). For these and other reasons, some authors have argued that it is inappropriate for researchers or advocates to pathologize victims who label their circumstances in ways that differ from the labels researchers or advocates prefer (Hamby 2014a).

The present research has the potential to reach one of the following three contrasting but equally important conclusions. The first possibility is that no evidence of substantial IPV over-reporting will be found. This possibility increases evidence about CTS validity. The second possibility is that there is evidence of over-reporting in a generalized pattern that occurs equally among different demographic groups (e.g. males and

6.45 females). This possibility implies that the CTS may exaggerate the extent of the IPV problem while having no implications about theories dealing with IPV's correlates or 6.47 aetiology. The third possibility is that there is evidence for differential over-reporting 
across demographic groups. A gendered pattern of this type has the potential (depending upon how substantial) to greatly affect existing IPV theories, which typically disagree about whether IPV perpetration and victimization rates are the same or different across gender (Johnson 1995). For this third reason, the current research concentrates upon understanding more about how gender affects IPV over-reporting, although additional factors affecting over-reporting are also examined.

\section{Method}

A computer-administered online survey with questions adopted from Straus and colleagues' CTS was developed by the author. The instrument was modified slightly for use with university-aged Australian populations by using contemporary terminology of the type commonly spoken by this group. A replication is currently underway at several US universities to determine whether the results of this research are country specific. Preliminary analyses on partially collected US data indicate that this is not the case. Furthermore, prior research suggests that the rates, distributions and causal factors associated with partner violence in Australia are quite similar to the United States (Headey et al. 1999). This further increases confidence that later analyses with US data will not differ in substantive ways from the findings presented here.

The survey retained the original CTS preamble and many of the original CTS items in a slightly modified form. The main portion of the question wordings for the victimization version of the CTS questions were as follows: (1) threw something at you that could or did hurt; (2) threatened to hit you or throw something at you; (3) slapped you; (4) pushed or shoved you; (5) used a gun or knife on you; (6) punched, hit or kicked you; (7) choked you. The perpetration version of the questions was modified to refer to the participant doing the act toward their partner. Survey administration differed in the following five subtle ways from traditional methods used by many IPV surveys that incorporate the CTS or similar partner violence scales.

First, respondents were asked about their relationship history. Those who indicated they had not engaged in at least one 'serious relationship' since high-school graduation were not administered the CTS portion of the survey. The term 'serious' was used after preliminary testing indicated that numerous university-aged respondents in Australia and the United States suggested this term as the one most commonly used among their peers to describe a relationship that had emotional attachment and involved more than one or two dates. Those who engaged in at least one 'serious' relationship since high school or who were married, engaged, divorced or involved with a common-law marriage (classified as a 'de facto relationship' in Australia) completed the CTS-type questions.

Second, rather than adhering to the traditional CTS method of asking respondents only about their current relationship, the study first determined how many 'serious relationships' the respondent had since high-school graduation and whether one was current. Respondents who had both a current and past partner were given IPV questions inquiring about events with both the current and the most-recent past partner. Respondents who indicated that they had only a current partner were asked only about this one individual, while those who indicated that they had dated a serious partner but were not doing so currently were asked about their most-recent past partner. We inquired about two partners because traditional administration methods that inquire 
only about current partners miss a substantial amount of violence during the high-risk times of separation and divorce (Taft et al. 2001), as well as violence that causes relationship dissolution (Ackerman 2012).

For example, no respondents reported gun or knife use by a current partner. There 8.5 were eight respondents, however, who reported that a past partner used such a weapon. Although no questions were included that might definitively determine whether a relationship was terminated because of a specific IPV act, this pattern is consistent with the interpretation that the eight past relationships involving weapon use were terminated as a specific result of the weapon use. If we had not inquired about past partners, we 8.10 would not have recorded any weapon use in the sample. There is also evidence from both clinical and research samples suggesting that IPV victims tend to deny abuse at early relationship stages (Hudson and McIntosh 1981). This suggests that participants may evaluate IPV events differently depending on whether discussing a current relationship in an early stage or a former relationship already terminated.

8.15 Asking about past partners overcomes these drawbacks, but adds complexity and length to the survey by requiring numerous skip/logic patterns, which alter the question

AQ7 sets presented to each respondent. The complexity makes computer administration necessary. Most prior research suggests that when all else is equal, computer-administrated surveys produce results similar to those obtained from traditional paper-and-pencil

8.20 formats (Hamby et al. 2006). Some research, however, suggests that computer-survey technology substantially increases disclosure of partner violence and other sensitive events in both medical and research settings (Turner et al. 1998; Rhodes and Al 2002).

Third, our survey asked a preliminary screening question to determine how often during disagreements, arguments or fights the respondent's partner either (1) insulted 8.25 or yelled; (2) broke, damaged or stole things; (3) threatened, followed or harassed; and (d) became physical in some way. This screening question was included due to the survey's length, which was a result of the inquiry about two partners, the additional follow-up questions for each positively endorsed CTS item, and the various scales and demographic information also collected. Respondents who indicated that none 8.30 of these behaviours had occurred were not asked about each CTS item individually. Although a preliminary screening question of this type is known to reduce prevalence estimates in certain situations relative to asking about each behaviour individually, it has benefits for the reduction of respondent fatigue, which can negatively affect answer quality (Ben-Nun 2008). Because the primary purpose was not to estimate IPV preva8.35 lence, this procedure seemed sound. A similarly worded screening question was asked for both current and past partners where applicable, as well as before subsequent question blocks addressing the respondent's perpetration of these behaviours directed to either a current or past partner.

Fourth, because there have been prior questions raised about the effect that inquiries about event frequency have on item interpretation (Gaskell et al. 1994), the respondents were asked how often an event occurred on a frequency-follow-up item only after indicating that the event in question occurred at least once on an initial screening question. Respondents who indicated that no event occurred on the screen question were not presented with the frequency-follow-up item containing the traditional CTS 8.45 response category listing of Once, Twice, 3-4 Times, 5-10 Times, 11-20 Times, More than 20 times, Never. The 'never' response was retained on the frequency-follow-up 8.47 item to provide the respondent three separate opportunities to report that each of the 
behaviour types had not occurred (the initial screening question, the CTS-type question about each behaviour and the frequency question about how often each behaviour occurred). The additional opportunities to correct an improper endorsement of an event that did not occur reduce respondent mistakes involving the selection of an erroneous response category.

Fifth, because relationships during late adolescence and early adulthood are often short lived, the survey inquired about events that occurred during the entire relationship rather than only during the last year as the CTS traditionally does. There are several examples of the use of this same time frame in prior IPV research (Smith 1994). Because the current study is not concerned about precise prevalence estimates, the time frame selected is not particularly relevant. Information about additional questions used for the current research is listed below.

\section{Sample}

The sample for the present study was drawn from students attending an Australian university operating from two different campuses during the 2014 academic year (March to December 2014). At this University, students may enrol in both traditional 'in-person' classes involving attendance at physical lectures, or 'online' classes where they watch recorded class sessions. Including online students permitted a more diverse participant sample, especially in terms of age.

Although some have questioned the use of student samples for research on IPVrelated topics, using student convenience samples is clearly advantageous in many situations, particularly when we consider that dating couples are even more likely to be violent than married couples (Straus 2004) and that university-aged students are near the peak of the crime-prone years (Hirschi and Gottfredson 1983). In addition, knowledge about young-adult populations is often considered particularly important given the fact that these individuals are in formative years of development when intervention for problematic behaviour is quite important.

Two samples were drawn using different methods. The first method involved sending participation invitations by email to students enrolled in courses that were mandatory for the University's criminology and criminal justice students. More specifically, student names and emails were obtained from university records for those enrolled in a first-year introductory course, a second-year forensic psychology course and a third-year research methods course. This resulted in 1,801 invitation emails being sent.

Prior to sending the emails, the author presented a brief project description to each class. Participation in this sample was limited to students who received the invitation email, which contained a web page link with an embedded password unique to each user. This method permitted each email recipient to complete one survey while preventing others from accessing the instrument. All participants in this sample, as well as the second sample, were offered the incentive of inclusion in a draw for one of several gift cards worth up to AUS $\$ 100$. A total of 611 students visited the survey's website and responded to at least some questions; 538 students completed the entire instrument. The response rate for this sample was 34 per cent $(611 / 1801)$, comparable to that of other online surveys administered at this university. 
The survey was administered to a second university sample several weeks later for the purposes of increasing sample size, diversifying the sample to other fields of study and permitting an evaluation of whether different sampling methods might produce different results. Interest in comparing various sampling strategies was motived by 10.5 anticipated future administrations of similar surveys that might use methods balancing cost with the introduction of sampling artefacts. For this second sample, the author coordinated with a university office that sends monthly announcement emails to all enrolled students about University research projects. Over 43,000 students received the announcement, which contained the survey's web page link, a project description and

10.10 the author's contact information. A total of 785 students responded by visiting the survey's website and answering at least some of the questions; 685 fully completed the online instrument. Due to the nature of the sampling method, no response rate can be calculated for this second sample.

The ratio of males to females in both samples was relatively low. Males comprised 16.9 10.15 per cent of the first sample and 21.3 per cent of the second sample. A somewhat lower proportion of males was expected in these samples for several reasons. First, the sampling frame for the first (students enrolled in criminology and criminal justice classes) was disproportionately female by a ratio of approximately 3 to 1 , the gender ratio of this field of study. Second, the sampling frame for the second was disproportionately 10.20 female by a ratio of 1.4 to 1 , the gender ratio of all fields of study at the university. Third, prior research in the survey design literature has consistently found that female survey response rates are higher than male response rates (Porter and Whitcomb 2005).

The response rate of the first sample (where response rate could be gauged), particularly that of males, is certainly far from ideal. Low response rates have the potential to 10.25 negatively affect the generalizability of research findings where low response results in non-response biases in cases where important differences exist between those who participate and those who do not. We must consider three things, however, when judging the potential effects of this response rate. First, low response does not necessarily correspond to non-response biases (Groves and Peytcheva 2008). Second, prior research has 10.30 generally suggested that the largest problem with survey response in IPV research is the potential for the most aggressive of males to refuse participation (Johnson 1995). We might expect that if this is the case, the current results simply represent conservative estimates of gender differences found in the current research (Ackerman 2012). Third, regardless of whether or not such biases exist, a primary purpose of this research is to 10.35 explore the degree to which respondents in IPV surveys misreport IPV events and thus negatively affect the accuracy of findings based upon survey data. For this reason, it may be ideal to replicate the response-rate characteristics of prior surveys from which findings about IPV have already been published. Stated in an alternative way, one might legitimately consider that the population to which the current research intends to gen10.40 eralize is not all of the country's university students but rather only those students prone to participate in IPV surveys.

After excluding 91 same-sex partnerships because there were too few for analysis in the current study, and those who did not have any 'serious' relationships after high-school graduation, the two samples jointly provided 974 usable surveys involving 10.45 opposite-sex partnerships. Because results did not vary in any substantial way across the samples (determined by conducting separate preliminary analyses), they were 10.47 combined. 


\section{Multi-level Analyses}

The main set of statistical analyses for the current study involved a three-level hierarchical logistic regression where a dichotomous indictor of over-reporting was regressed on person-, relationship-, and event-level characteristics. Multi-level/hierarchical models have been well established in the criminology literature (Raudenbush and Bryk 2002), and the nature of the present analyses permits the results to be interpreted essentially similarly to a traditional logistic regression. For these reasons, few details of this method are presented here.

The most important detail to note is that multi-level models are useful to provide appropriate standard error calculations for data in a 'nested' format (Schwartz and Ackerman 2001). Models that do not account for this format violate regression assumptions requiring independent observations. A common form of 'nesting' is when several different non-independent measurements are included for each research participant. In the present case, several participants had more than one relationship, and all were asked whether or not various forms of partner violence occurred within each. Although I was unable to locate prior research in the criminological literature that has applied a similar multi-level model to the study of IPV, medical research has utilized parallel multi-level analyses when comparing event endorsements with different IPV screening instruments (MacMillan et al. 2006).

The three analysis levels are as follows:

Level 3: $N=974-$ There were 974 respondents who provided data necessary for the present analyses.

Level 2: $N=1,088$-Each of the 974 participants was asked questions that determined whether they had current and/or past romantic partners. Some participants had current partners, some had past partners and some had both. Because 114 participants reported on two partners, there are more relationships than participants. The multilevel model accounts for the non-independence of the two relationships per person.

Level 1: $N=15,232$-Each participant was asked seven questions about victimization at the hands of their partner and seven corresponding questions about perpetration against their partner. Because there were 1,088 relationships included in the sample, the $N$ at the event level (level 1 ) is $1,088 * 14=15,232$ ( 7 victimization and 7 perpetration questions per relationship). This represents the fact that each respondent had 14 opportunities to report (and thus over-report) either a victimization or a perpetration for each relationship regardless of whether or not they did so.

\section{Variables}

\section{Dependent variable}

Over-reporting-If a respondent endorsed one of the seven CTS-type questions about whether they were victimized, the computer-administered survey next asked about the frequency with which the act occurred. The frequency question was followed by a 'multiple-choice' question inquiring about the context of the event. 'Multiple-choice' refers to a question type where the respondent may select from one or more response-alternatives [not mutually exclusive] by checking appropriate boxes on the internet-based web form. The context question for each of the seven victimization items began, 'Which of the following apply to the most serious incident when [your partner] [event]?', where 
[your partner] refers to either 'Current Partner' or 'Past Partner' and [event] refers to one of the seven CTS-type items. The context question contained eight response possibilities addressing the degree of injury, the intentionally of the act and other pertinent event details. The two responses relevant for the over-reporting measure of current 12.5 interest are 'Accident' and 'Joking, playful or humorous-no one took it seriously'. If the respondent endorsed one of the CTS items and subsequently indicated that either (or both) of these two event details were applicable, the endorsement was considered an over-report. In other words, if a participant interpreted the questions in a very literal way, she or he may have reported acts such as slapping and hitting during initial

12.10 questioning that an independent observer would not have classified as true partner violence. When asked follow-up questions about the context, however, a better indication of the event's nature becomes apparent. Similar procedures were followed for determining whether over-reports occurred for questions about respondent perpetration against both current and former partners using minor alterations to the question

12.15 wording and response categories as appropriate.

\section{Independent variables}

Event level (level 1)

12.20 Victimization/perpetration-Questions pertaining to victimization were coded 1, while questions pertaining to perpetration were coded 0 . Because each participant was asked seven victimization and seven perpetration questions for each relationship (current and past), each relationship/participant combination contains 14 data rows where seven are coded 1 and seven coded 0 .

12.25

\section{Relationship level (level 2)}

Past/current partner-Each of the 974 participants was asked questions that determined whether she or he had current and past romantic partners. Some participants had current partners, some had past partners and some had both. Questions related to current partners were coded 1, while questions related to past partners were coded 0 . This variable was included to determine whether differences occur in over-reporting for current versus past partners for several reasons including the fact that participants may re-assess the meaning and interpretation of partner intention

12.35 after a relationship ends.

Mutual reports-If a participant reported one or more victimizations and one or more perpetrations for any of the seven CTS events for the same partner, the relationship was coded as a mutual report. Prior literature has alternatively described this as $b i$ directional aggression (Vivian and Langhinrichsen-Rohling 1994). Participants were

12.40 classified in this way regardless of the event type reported. For example, if a current partner punched a participant and the same participant slapped the current partner, the current relationship was classified a mutual report.

Person level (level 3)

Gender/male-The 974 respondents included in the sample were asked about their biological sex. This was coded 1 for male and 0 for female. 
Age-The original question about respondent age contained 11 different categories starting at age 17, which is the legal age for research consent in Australia. The specific categories were ' $17,18,19,20,21,22,23,24-30,31-40,41-50$, over 50'. An interval-level age variable was created from these categories by substituting the mid-points of the 24-30, 31-40 and 41-50 categories, while 55 was used for the 23 respondents in this oldest age group. The approximate mean of 25 was substituted for the three respondents who did not answer. This variable was included because age is associated with both maturity and experience in romantic partnerships. It was assumed that more mature and experienced individuals are less likely to over-report IPV because they have a better understanding of the seriousness of partner violence and are therefore less likely to mix accidents and playful behaviour with purposeful and consequential aggressive acts.

\section{Hypotheses}

Several of the present analyses are of a mostly descriptive nature, intended primarily to ascertain the extent of the over-reporting problem for both male and female research participants. As such, gender comparisons presented in Table 2 are not intended to directly test specific hypotheses. The multi-level analyses presented in Table 3, however, are intended to test hypotheses adopted from various claims found in the IPV literature. These are best articulated by Kimmel in a thorough review article written from a feminist perspective (2002). Although Kimmel did not articulate precise statements directly translatable into quantitative terminology, he expressed statements roughly corresponding to the following hypotheses:

Hypothesis 1-Males and females are likely to over-report IPV events to a different degree (whether victimizations or perpetrations).

Hypothesis 2-Males are particularly likely (relative to females) to over-report being victimized by female partners in relationships involving mutual aggression. Kimmel explains that this may be the case because aggressive males may attempt to justify their aggressive acts by over-reporting their partner's aggression towards them (i.e. 'I hit her because she hit me first'). More specifically, there will be a [cross-level] interaction between gender and mutual aggression.

-Males are particularly likely (relative to females) to over-report IPV events involving

Hypothesis 3 - Males are particularly likely (relative to
victimization rather than perpetration.

\section{Results}

Table 1 provides several important characteristics of the sample's 974 participants who provided information about 1,088 current and prior romantic relationships. Consistent with the nature of the University's student population, most participants were between 17 and 30 years old (over 75 per cent). Although the number of older students would likely be considered high by the standards of some countries, the figures are typical for Australian universities where a sizable number of individuals complete university education part time during later life stages.

Participants with current partners but not prior partners comprised 62.8 per cent of the sample. Those with past partners but not current partners were 25.5 per cent, while those with both current and past partners were 11.7 per cent. Mutual reporters comprised 4 per cent of the sample where respondents reported perpetration against their partner and victimization by the same partner.

Page 13 of 22 
Table 2 provides male versus female comparisons of IPV reporting, and over-reporting rates as both a victim and a perpetrator. As mentioned above, over-reporting refers to cases where the participant endorses a CTS item but subsequently indicates that the event was either accidental or done in jest where neither partner took the event seri14.5 ously. The first data row indicates that 21.8 per cent of males reported being victims of some type of IPV during the course of the relationship. This is a far greater percentage than the 14.1 per cent of females making these reports, but consistent with prior research conducted in several countries, which indicates that males typically report victimizations at a greater rate than females (Straus 2008). A chi-square test indicates 14.10 that the gender differences are statistically significant at the $p=0.01$ level.

Of primary interest is the second data row. This shows that almost one-quarter (23.4 per cent) of the victimizations reported by the males were subsequently classified as over-reports. Females also had substantial rates of over-reporting, but those rates were only 12.9 per cent, nearly half as much as the male over-reporting rate. Again, a chi14.15 square test indicates that this difference is statistically significant at the $p<0.01$ level. Note that the figures reported on this row do not strictly mean that 23.4 and 12.9 per cent of the reports indicated on the prior row for males and females, respectively, are

TABLE $1 \quad$ Sample descriptives

AQ15

14.35

TABLE 2 IPV report and over-report rates

\begin{tabular}{lrr}
\hline & $N$ & $\%$ \\
\hline Age & & 349 \\
$17-20$ & 208 & 21.4 \\
$21-23$ & 210 & 21.6 \\
$24-30$ & 135 & 13.9 \\
$31-40$ & 59 & 6.1 \\
$41-50$ & 23 & 2.4 \\
$50+$ & 156 & 16.0 \\
Male & 612 & 62.8 \\
Has current partner only & 248 & 25.5 \\
Had past partner only & 114 & 11.7 \\
Both current and past partner & 39 & 4.0 \\
Mutual victimization reports & 974 & \\
No. of respondents in sample & 1,088 & \\
No. of relationships in sample & & \\
\hline
\end{tabular}

14.30 Both current and past partne

\begin{tabular}{lrr}
\hline & Males & Females \\
\hline $\begin{array}{l}\text { Victimization } \\
\text { Respondents reporting one or more victimisations in either }\end{array}$ & $21.8 \%$ & $14.1 \%$ \\
$\quad \begin{array}{l}\text { current or past relationship }\left(\chi^{2}=6.05, \mathrm{df}=1, p=0.01\right) \\
\text { Victimization reports that are over-reports }(\chi\end{array}$ & $23.4 \%$ & $12.9 \%$ \\
$\quad \begin{array}{l}\text { Respondents over-reporting one or more IPV victimizations in } \\
\text { either current or past relationship }\left(\chi^{2}=9.73, \mathrm{df}=1, p<0.01\right)\end{array}$ & $8.3 \%$ & $3.1 \%$ \\
Perpetration & & $7.1 \%$ \\
$\quad \begin{array}{l}\text { Respondents reporting one or more perpetrations in either } \\
\text { current or past relationship }\left(\chi^{2}=5.08, \mathrm{df}=1, p=0.02\right)\end{array}$ & $47.6 \%$ & $13.6 \%$ \\
Perpetration reports that are over-reports $(\chi$ & $2.6 \%$ & $17.0 \%$ \\
$\quad \begin{array}{l}\text { Respondents over-reporting one or more IPV perpetrations in } \\
\text { either current or past relationship }\left(\chi^{2}=0.23, \mathrm{df}=1, p=0.63\right)\end{array}$ & $3.3 \%$ \\
\hline
\end{tabular}


over-reports because the figures on this row are based upon all victimization reports from all participants (up to seven possible victimization reports per relationship) regardless of whether each participant reported only one victimization or several.

The third data row indicates over-reporting rates in an alternative manner. While the prior data row provides over-reporting percentages based upon the number of reports as the denominator, this third row provides over-reporting percentages based upon the total number of participants in each gender category as the denominator. Here, we also see that the male participants were over 2.5 times more likely to over-report one or more IPV events than were the female participants. The chi-square test indicates that this difference is statistically significant at the $p<0.01$ level.

Perpetration rates are presented in data rows three through six. Row 3 indicates that 7.1 per cent of the males reported perpetrating at least one of the seven types of IPV, while 13.6 per cent of the females reported perpetration. Again, this difference is statistically significant at the $p<0.01$ level.

The largest of the gender differences are shown in the fifth data row. Here, we see that of the male perpetrations reported on the prior data row, 47.6 per cent were subsequently classified as over-reports, while only 17 per cent of the female endorsements were so classified. As before, this difference is statistically significant at the $p<0.01$ level.

The only gender difference not statistically significant at the 0.05 level or better is shown on the sixth data row. Here, we see that 2.6 per cent of the male versus 3.3 per cent of the female participants in the sample had one or more perpetration over-reports.

Table 3 presents the main set of analyses. Three multi-level logistic regression models are presented where the first is a base model containing only main effects, while the second and third add interaction terms corresponding to Hypotheses 2 and 3. Rather than presenting different tables for perpetration and victimization as in Table 2 , these are presented in the same models where a victimization versus perpetration dichotomous indicator is included as an event-level control.

Note that all independent variables with the exception of age are dichotomous. Because the dichotomous variables have the same metric, the magnitude of their regression coefficients may be directly compared. Also note that most of models in Table 3 are not directly comparable to the gender comparisons in Table 2 because some analysis units differ substantially. For example, the percentage of over-reported perpetrations and victimizations on Rows 2 and 5 in Table 2 include only those cases initially reported as IPV. In contrast, analyses presented in Table 3 are based upon the complete sample of 15,232 event scenarios where over-reports might potentially occur.

Supporting Hypothesis 1, Model 1 in Table 3 indicates that males are significantly more likely than females to over-report IPV events. The odds of a male respondent over-reporting are over double that of a female respondent. Also noteworthy, older individuals were less likely than younger ones to over-report as were those in current (versus past) relationships. In addition, participants were more likely to over-report victimizations than perpetrations. Mutual aggression within couples was by far the strongest effect of the independent variables, predicting over 36 times higher odds of over-reporting relative to relationships where only victimization or only perpetration was reported. An odds ratio (OR) this high means that essentially all of both the victimization and perpetration aspects of mutual aggression were over-reports.

Model 2, which added the [cross-level] interaction of male $\times$ mutual aggression, did not support Hypothesis 2. There was no meaningful evidence supporting the prospect 
ACKERMAN

16.5

16.15

16.20

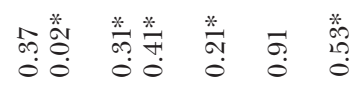

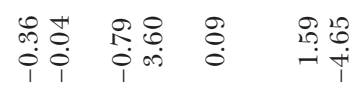

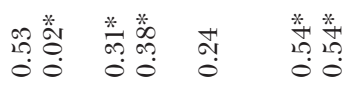

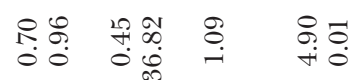

16.10

16.25

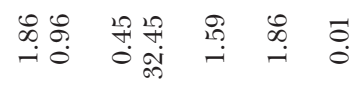

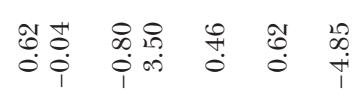

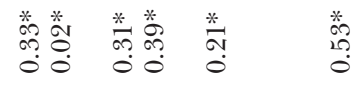

16.30

16.35

16.40

16.45

16.47 
that males are particularly likely to over-report within relationships characterized by mutual aggression relative to those where the male was either victim or aggressor but not both. Stated in an alternative way, mutual aggression was an equally strong predictor of over-reporting for both males and females.

Model 3 added the [cross-level] interaction of male $\times$ victimization and supported Hypothesis 3. Males were significantly more likely to over-report victimizations than perpetrations. Notice that when this interaction term was added, the main effect of victimization dropped substantially (to non-significance) from 0.46 in Model 1 to 0.09 in Model 3. This indicates that essentially all of the higher rates of victimization overreporting (relative to perpetration over-reporting) shown in Model 1 are due to the over-reporting of victimization by males. This can be seen in alternative form by comparing data rows 3 and 6 in Table 2. Here, we see that the rate of female over-reporting of victimization is 3.1 per cent versus 3.3 per cent for perpetration, while the rate of male over-reporting of victimization is 8.3 per cent versus 2.6 per cent for perpetration. In other words, males and females had roughly similar (non-significant) rates of perpetration-over-reporting, while males had much higher rates of victimization-overreporting than did the females. As noted earlier, this finding does not contradict Row 5 of Table 2 because the analysis units are much different. When the findings from the two tables are combined, they suggest that when males are asked about whether there has been an IPV event involving a female partner, the males are more likely than the females to respond affirmatively in a way unintended by the survey design and that the males do this far more often when asked whether a female has victimized them compared with when asked whether they have victimized a female (perpetrated an IPV event against a female). However, when males do report a perpetration (which they admit to a lesser degree than do females), nearly one-half (47.6 per cent) of their reported perpetrations are over-reports.

\section{Discussion}

These analyses clearly show that misreporting is potentially a serious problem in IPV surveys relying upon scales such as the CTS—at least among Australian university students. Although critics of university samples might be sceptical of the results, they might consider that if reasonably well-educated students interpret questions about IPV in ways unintended by survey administrators, the interpretations of the less well educated are likely to diverge from what was intended to an even greater degree. In addition, preliminary results from a replication currently underway at various US universities suggest that the problem is not confined to this country. Instead, the problem appears more widespread and is of a nature that demands more investigation, especially given over-reporting's gendered nature, the extent to which the CTS is used in a variety of research studies and the reliance upon those results to inform theories about IPV. Most importantly, the current findings suggest that several theoretical claims made by feminist theory, but not previously supported by empirical data, deserve re-evaluation using methods that can potentially ameliorate over-reporting and other forms of systematic measurement error.

An important question that cannot be definitely answered by the present study relates to the mechanisms underlying the over-reports. Although some prior literature suggests the possibility that some type of intentionality underlies over-reports, particularly 
by males, several patterns presented in this study point towards unintentional mechanisms, i.e. unconscious motivations characterized primarily by what the survey design literature classifies as 'meaning shifts' by the respondents (Gaskell et al. 1994). In other words, mechanisms where the respondents attribute a different meaning to the survey 18.5 question then had been intended by the survey designer. If respondents were primarily motivated to intentionally fabricate IPV events that did not occur, it would be unlikely for them to reverse this fabrication by indicating the event's benign context in follow-up questions. In contrast, the current results are more likely a result of respondents altering (or misinterpreting) the meaning of the over-reported items to something of a very

18.10 literal nature beyond the intent of the survey design.

This interpretation is also consistent with the pattern found with mutual reports. When mutual reports of aggressive behaviour are present, over-reports are much more likely. At the same time, the effect of mutual reporting does not substantially differ across gender. A likely explanation is that respondents inclined to interpret questions 18.15 in a literal way when reporting about their partner's behaviour are equally likely to use a literal interpretation when reporting about the behaviour they direct towards their partners.

The fact that males are more likely to over-report victimizations than perpetrations (as evidenced by the male $\times$ victimization interaction), however, does potentially

18.20 suggests a more purposeful motivation on the part of the males (i.e. if males were simply interpreting the questions more literally than women and thus more likely to over-report benign actions, we would expect them to apply the literal interpretation equally to victimization and perpetration). The male $\times$ victimization interaction effect $(\mathrm{OR}=4.90)$, however, is dwarfed by the effect of mutual aggression, which has an OR 18.25 of 36.8. Although the exact interpretation of these patterns is somewhat speculative, what is clear is that females are much less prone to both victimization and perpetration over-reports of this type than males.

Age is another important factor in explaining over-reporting. Increases in age are associated with decreases in over-reporting. A ten-year age difference is associated with 18.30 a 23 per cent decrease in the odds of over-reporting $\left(e^{-4}=0.67\right)$. This effect suggests that as individuals mature, they are more likely to properly interpret the underlying intent of IPV questions. Alternatively, older individuals may be less likely to engage in the types of behaviours towards their partners that might result in over-reporting even if they continue to interpret CTS questions in equally literal ways.

18.35

\section{Conclusion}

This manuscript clearly indicates that at least some of the concerns raised by theorists taking a feminist perspective about the overall validity of the CTS, as well as the dif-

18.40 ferential validity of this instrument across gender, are justified, at least when this scale is administered to university-aged samples. The results suggest that over-reporting of partner violence events is a potentially serious problem for testing theories of IPV that rely upon the analysis of CTS data. The gendered patterns illustrated in this study point to the possibility that not only will over-reporting affect IPV prevalence estimates

18.45 but that the problem has the potential to misinform our understanding of IPV's aetiology-at least in circumstances where accurate assessment of gender differences in

18.47 aggression is important. The type of over-reporting examined here, however, decreases 
across age. Because the current sample includes few older adult individuals, the current data cannot be used to determine the degree to which over-reporting is likely to occur among the older individuals most likely to come into contact with victim advocates and the criminal justice system-the two primary sources of the alternative forms of data that produce results largely inconsistent with those obtained from survey data.

Tasks of future research include not only replicating this study using a similar instrument on older adult samples but also determining the degree to which the gendered patterns of over-reporting found in this study are strong enough to potentially explain why the findings of prior research are often inconsistent across data type. An additional task for future research is to determine how best to correct this problem and the degree to which corrections affect the testing of various IPV theories. Most likely, the correction is best made by removing IPV event endorsements subsequently identified as being outside the conceptual understanding of what constitutes an actual partner violence event.

The current research is not without its limitations, of course. Along with previously mentioned limitations, it examined IPV over-reporting only on the types of items found on Straus and colleagues' CTS. Additional research is necessary to determine whether the same degree of over-reporting is present on other scales using alternative terminology. According to theories found within the survey design literature, using more specific terminology should decrease the ambiguity of survey item wording, which should produce fewer over-reporting problems. The fact that important psychometric properties of some of the alternative scales are based upon the CTS as a criterion measure emphasizes the need to thoroughly examine the CTS as a preliminary step before applying similar methods to these alternative scales.

This study's results might tempt some to make a pre-mature conclusion that we should abandon the use of surveys in IPV research. This solution is problematic because survey data is often the force driving policy initiatives (Bart et al. 1989) and the type of data used to assess the validity of theories about IPV aetiology. Moreover, a great deal of evidence suggests that IPV victims generally prefer self-completed questionnaires over face-to-face questioning in clinical settings (MacMillan et al. 2006).

Rather than abandon survey research, a better alternative is to determine through additional exploration the degree to which various forms of misreporting occur, how the problem affects research conclusions and the best ways to correct this problem. As explained by DeKeseredy and Schwartz, 'perfect surveys on violence against women are not possible, but good ones can and should be done' (1998: 5).

\section{Funding}

This work was supported by Griffith University Criminology Institute and Griffith University Arts, Education, and Law Academic Group research grants.

\section{AcKnowledgements}

The author wishes to acknowledge the assistance of his research staff, particularly Veya Seekis and Abigail Rutledge, who contributed to the development of the survey instrument used in this study. He also wishes to acknowledge the contributions of Christina Murphy, Li Erikksson, Christine Bond and the anonymous reviewers for their helpful suggestions, careful review and critique of this manuscript. 
ACKERMAN

\section{REFERENCES}

Ackerman, J. (2012), 'The Relevance of Relationship Satisfaction and Continuation to the Gender Symmetry Debate'. Journal of Interpersonal Violence, 27: 3579-600.

20.5

Bart, P. B., Miller, P. Y., Moran, E. and Stanko, E. A. (1989), 'Editors' Introduction'. Gender and Society, 3: 431-6.

Bates, E. A., Graham-Kevan, N. and Archer, J. (2014), 'Testing Predictions from the Male Control Theory of Men's Partner Violence'. Aggressive Behavior, 40: 42-55.

Beatty, P. C. and Willis, G. B. (2007), 'Research Synthesis: The Practice of Cognitive Interviewing'. Public Opinion Quarterly, 71: 287-311.

20.10 Belson, W. (1981), The Design and Understanding of Survey Questions. Gower.

Ben-Nun, P. (2008), 'Respondent Fatigue'. in P. J. Lavrakas, ed., Encyclopedia of Survey Research Methods, 743-4. Sage.

DeKeseredy, W. S. (1995), 'Enhancing the Quality of Survey Data on Woman Abuse: Examples from a National Canadian Study'. Violence Against Women, 1: 158-73.

20.15

DeKeseredy, W. S. and Schwartz, M. D. (1998) Measuring the Extent of Woman Abuse in Intimate Heterosexual Relationships: A Critique of the Conflict Tactics Scales. VAWNet: National Online Resource Center on Violence Against Women.

Dobash, R. P., Dobash, R. E., Wilson, M. and Daly, M. (1992), 'The Myth of Sexual Symmetry in Marital Violence'. Social Problems, 39: 71-91.

20.20 Farrall, S., Bannister, J., Ditton, J. and Gilchrist, E. (1997), 'Questioning the Measurement of the 'Fear of Crime': Findings from a Major Methodological Study'. British Journal of Criminology, 37: 657-78.

Felson, R. B., Ackerman, J. and Yeon, S.-J. (2003), 'The Infrequency of Family Violence'. Journal of Marriage and Family, 65: 622-34.

20.25 FodDy, W. (1993), Constructing Questions for Interviews and Questionnaires: Theory and Practice in Social Research. Cambridge University Press.

Fuchs, M. (2008) 'Overreporting'. in P. J. Lavrakas, ed., Encyclopedia of Survey Research Methods, 561-2. Sage.

20.30 Gadd, D., Farrall, S., Dallimore, D. and Lombard, N. (2002), Domestic Abuse against Men in Scotland. Scottish Executive Central Research Unit.

Gartner, R. I. (1993), 'Studying Women Abuse: A Comment on Dekeseredy and Kelly'. Canadian Journal of Sociology, 18: 313-20.

Gaskell, G. D., O’muircheataigh, C. A. and Wright, D. B. (1994), 'Survey Questions

20.35 About the Frequency of Vaguely Defined Events: The Effects of Response Alternatives'. Public Opinion Quarterly, 58: 241-54.

Gelles, R. J. and Straus, M. A. (1979), 'Determinants of Violence in the Family: Toward a Theoretical Integration', in W. R. Burr, R. Hill, F. I. Nye and I. L. Reiss, eds., Contemporary Theories About the Family, 549-81. Free Press.

20.40 Groves, R. M. and Peytcheva, E. (2008), 'The Impact of Nonresponse Rates on Nonresponse Bias: A Meta-Analysis'. Public Opinion Quarterly, 72: 167-89.

Hamby, S. (2014a), Battered Women's Protective Strategies: Stronger Than You Know. Oxford University Press.

- (2014b), 'Intimate Partner and Sexual Violence Research: Scientific Progress, Scientific Challenges'. Trauma, Violence, E Abuse, 15: 149-58.

20.45 Hamby, S., Sugarman, D. B. and Boney-Mccoy, S. (2006), 'Does Questionnaire Format Impact Reported Partner Violence Rates?: An Experimental Study'. Violence and Victims, 21: 507-18. 
Headey, B., Scott, D. and De Vaus, D. (1999), 'Domestic Violence in Australia: Are Women and Men Equally Violent?'. Australian Social Monitor, 2: 57-62.

Hirschi, T. and Gottfredson, M. R. (1983), 'Age and the Explanation of Crime'. American Journal of Sociology, 89: 552-84.

Hudson, W. W. and McIntosh, S. R. (1981), 'The Assessment of Spouse Abuse: Two Quantifiable Dimensions'. Journal of Marriage and Family, 43: 873-85.

Johnson, M. P. (1995), 'Patriarchal Terrorism and Common Couple Violence: Two Forms of Violence against Women'. Journal of Marriage and Family, 57: 283-94.

Kimmel, M. S. (2002), 'Gender Symmetry in Domestic Violence'. Violence Against Women, 8: 1332-63.

Kline, E., Campbell, J. C., Soler, E. and Ghez, M. (1997), Ending Domestic Violence: Changing Public Perceptions/Halting the Epidemic. Sage.

LANGhinrichsen-Rohling, J. (2005), 'Top 10 Greatest "Hits": Important Findings and Future Directions for Intimate Partner Violence Research'. Journal of Interpersonal Violence, 20: $108-18$.

Lehrner, A. and Allen, N. E. (2014), 'Construct Validity of the Conflict Tactics Scales: A Mixed-Method Investigation of Women's Intimate Partner Violence'. Psychology of Violence, 4: 477-90.

MacMillan, H. L., Wathen, C. N., Jamieson, E., Boyle, M., Mcnutt, L.-A., Worster, A., Lent, B. and Weвb, M. (2006), 'Approaches to Screening for Intimate Partner Violence in Health Care Settings: A Randomized Trial'. Journal of the American Medical Association, 296: 530-6.

Margolin, G. (1987), 'The Multiple Forms of Aggressiveness between Marital Partners: How Do We Identify Them?'. Journal of Marital and Family Therapy, 13: 77-84.

Messing, J. T. and Thaller, J. (2013), 'The Average Predictive Validity of Intimate Partner Violence Risk Assessment Instruments'. Journal of Interpersonal Violence, 28: 1537-58.

Pagelow, M. D. (1979), 'Research on Woman Battering'. in J. B. Fleming, ed., Stopping Wife Abuse. Anchor.

Porter, S. R. and Whitcomb, M. E. (2005), 'Non-Response in Student Surveys: The Role of Demographics, Engagement, and Personality'. Research in Higher Education, 46: 127-52.

Raudenbush, S. W. and Bryk, A. S. (2002), Hierarchical Linear Models. Sage.

Reichenheim, M. E. and Moraes, C. (2004), 'Comparison between the Abuse Assessment Screen and the Revised Conflict Tactics Scales for Measuring Physical Violence During Pregnancy'. Journal of Epidemiology and Community Health, 58: 523-7.

Rhodes, K. V. and Al., E. (2002), “Between Me and the Computer”: Increased Detection of Intimate Partner Violence Using a Computer Questionnaire'. Annals of Emergency Medicine, 40: 476-84.

Saunders, D. G. (1986), 'When Battered Women Use Violence: Husband-Abuse or SelfDefense?'. Violence and Victims, 1: 47-60.

Schwartz, J. and Ackerman, J. (2001), 'In Search of a Dependent Variable: A Comment on Avakame, 1998'. Criminology, 39: 969-79.

Sмiтh, M. (1994), 'Enhancing the Quality of Survey Data on Violence against Women: A Feminist Approach'. Gender and Society, 8: 109-27.

Straus, M. A. (1979), 'Measuring Intrafamily Conflict and Violence: The Conflict Tactics (Ct) Scales'. Journal of Marriage and Family, 41: 75-88.

. (2004), 'Prevalence of Violence against Dating Partners by Male and Female University Students Worldwide'. Violence Against Women, 10: 790-811. 
(2008), 'Dominance and Symmetry in Partner Violence by Male and Female University Students in 32 Nations'. Children and Youth Services Review, 30: 252-75.

Sullivan, T. P., Schroeder, J. A., Dudley, D. N. and Dixon, J. M. (2010), 'Do Differing Types of Victimization and Coping Strategies Influence the Type of Social Reactions 22.5 Experienced by Current Victims of Intimate Partner Violence?'. Violence Against Women, 16: $638-57$.

Sutton, R. M. and Farrall, S. (2005), 'Gender, Socially Desirable Responding and the Fear of Crime: Are Women Really More Anxious About Crime?'. British Journal of Criminology, 45: 212-24.

22.10 Taft, A., Hegarty, K. and Flood, M. (2001), 'Are Men and Women Equally Violent to Intimate Partners? '. Australian and New Zealand Journal of Public Health, 25: 498-500.

Tourangeau, R., Rips, L. J. and Rasinski, K. (2000), The Psychology of Survey Response. Cambridge University Press.

Turner, C. F., Ku, L., Rogers, S. M., Lindberg, L. D., Pleck, J. H. and Sonenstein, F. L. 22.15 (1998), 'Adolescent Sexual Behavior, Drug Use, and Violence: Increased Reporting with Computer Survey Technology'. Science, 280: 867-73.

Vivian, D. and Langhinrichsen-Rohling, J. (1994), 'Are Bi-Directionally Violent Couples Mutually Victimized? A Gender-Sensitive Comparison'. Violence and Victims, 9: 17.

Willis, G. B. and Schecter, S. (1997), 'Evaluation of Cognitive Interviewing Techniques:

22.20 Do the Results Generalize to the Field?'. Bulletin de Methodologie Sociologique, 11: 40-66. 